\title{
Sobre el Absoluto. Homenaje a Juan Noemi
}

\author{
Luis Mariano de la Maza \\ INSTITUTO DE FILOSOFÍA \\ PONTIFICIA UNIVERSIDAD CATÓLICA DE CHILE \\ sdel4@uc.cl
}

Considero una gran honra el haber sido invitado a decir unas palabras en el merecido homenaje que se rinde hoy al profesor Juan Noemi, a pesar de no ser teólogo de profesión. Creo que la razón por la que estoy en este lugar es una cierta comunidad espiritual en torno a temas comunes a la teología y la filosofía que hemos podido discutir como colegas a lo largo de muchos años de fructífero intercambio académico en seminarios y encuentros de naturaleza interdisciplinaria. Nos une un cierto gusto por el pensamiento especulativo, que no contraponemos al pensamiento práctico, sino que es más bien la condición para que este último se realice sobre bases sólidas y efectivas. Pero también sabemos que la especulación teórica recibe impulsos de renovación y actualización a partir de la interpretación del presente o la lectura de los signos de los tiempos que realiza el pensamiento práctico para cumplir con su finalidad de llevar al ser humano a formas de vida más justas y plenas.

Hojeando el libro de Juan sobre la Credibilidad del Cristianismo que hoy ve la luz junto al libro de homenaje que se le dedica, encontré un título que me resulta muy estimulante para comenzar esta presentación: "Absolutez y relatividad del cristianismo." La tensión entre lo absoluto y lo relativo, lo infinito y lo finito, la verdad y la historia, mediados por la razón filosófica y teológica que buscan dar cuenta y hacer justicia a ambos términos sin anular a uno de ellos en aras del otro es de lo que quisiera reflexionar, sin pretender ni remotamente abarcar toda la hondura de este problema.

En el capítulo mencionado, Juan recoge el desafío planteado por la filosofía de Hegel en el 
primer tercio del siglo XIX, que, según su descripción "consiste en pensar o articular "conceptualmente» una absolutez verdadera", la que no excluye sino que debe incluir la multiplicidad de lo finito y su relatividad histórica, tal como se lo representa la religión cristiana con la encarnación de Dios en el hombre". En el capítulo se distinguen dos sentidos de lo absoluto. El primero de ellos es negativo, pues alude a la exclusión de toda relación, y por lo tanto se refiere a lo real en tanto que uno contrapuesto a lo múltiple y diverso. El segundo sentido, en cambio, es positivo, pues relaciona lo absoluto con lo relativo en tanto que lo acoge como su fundamento sustentador. Este segundo sentido no renuncia a la unidad, pero la entiende como universalidad en la que las diferencias no son anuladas, sino integradas como partes suyas.

Noemi afirma que el discurso sobre lo absoluto y la pretensión de absolutez del cristianismo tiene un sentido legítimo y vigente en la medida que refiere y tematiza la recepción de todo lo finito y relativo por parte del mismo Dios en Jesucristo. La encarnación de Dios significa que Dios renuncia a su absolutez en sí y para sí y se entrega a la relatividad de la historia como Jesús de Nazaret. Hace propio lo relativo sin confundirse ni separarse de ello.
De este modo la absolutez no está en contraposición a la relatividad, sino que es un atributo de la relatividad histórica de la humanidad, es decir de la historia de todos y cada uno de los seres humanos. En este sentido habla Noemi de la "absoluta relatividad del cristianismo". Ciertamente no está defendiendo con ello un relativismo absoluto, como podría pensar escandalizada alguna de esas personas que se dejan llevar por la primera impresión que le producen las palabras y andan buscando motivos para acusar a otros de errores y herejías. Lo que está en juego no es una exacerbación del relativismo, sino todo lo contrario, una superación del mismo al integrarlo al absoluto, sin incurrir en el exceso contrario de anularlo negándole toda consistencia. Lo relativo y finito es redimido en el absoluto, pero, como afirmaba San Ireneo de Lyon, solo se redime lo que se asume.

No cabe duda que en este punto hay en esto una coincidencia con el pensamiento de Hegel, aunque con una importante salvedad. En la $\mathrm{Fe}$ nomenología del espiritu de Hegel se encuentra la frase que Noemi suele citar: "Solo lo absoluto es verdadero o lo verdadero solo es absoluto". La Fenomenología es la obra en la que Hegel procura restaurar la unidad entre el sujeto y el objeto como 
unidad de lo finito y lo infinito que habían sido separados en el origen de la filosofía moderna. Socavando la rígida oposición entre sujeto que conoce y objeto conocido, Hegel presenta a la razón como un proceso de búsqueda y desocultamiento de la verdad, que es a la vez un proceso de absolución de toda relatividad. Absolución o absolvencia de la relatividad del saber finito es el término mediante el cual Heidegger designa el movimiento de la Fenomenología en una de sus lecciones dedicadas a la obra de Hegel. Heidegger llama «absolvencia» (Absolvenz) al saber en el que la conciencia es liberada de su estado de absorción en las cosas para saberse a sí misma como autoconciencia. Equivale, a una liberación de lo relativo, cuyo resultado es la ciencia o el saber absoluto. Sin embargo este resultado no es, a mi juicio, plenamente consecuente con la motivación original del propio Hegel, pues tan importante como el carácter absoluto de lo relativo, es también, subrayar, como lo hace Juan Noemi, la relatividad de lo absoluto.

La filosofía actual ha aprendido que la razón no puede pasar por alto la finitud humana, por lo que no puede llegar a realizar jamás el ideal de un saber total, perfecto, completo e incondicionado, como es la pretensión de un saber abso- luto. Los problemas sistemáticos de la filosofía y de la teología no se pueden separar completamente de la historia de su génesis, su desarrollo, sus condicionamientos y de lo que queda por descubrir. Las cuestiones sistemáticas e históricas se complementan e iluminan mutuamente, siempre que se entienda que la esencia de la historia no consiste en la mera restitución del pasado.

La perspectiva histórica no significa olvidarse de sí mismo para desplazarse al pasado olvidando el presente, sino todo lo contrario: es un llevarse a sí mismo, con los propios pensamientos y creencias, con la propia comprensión de las tareas y desafíos que plantean los tiempos actuales, hacia otra situación, en la que estos pensamientos, creencias y desafíos se someten a examen crítico y se ponen en el terreno de lo discutible. El examen crítico exige interrogar lo que nos viene desde el pasado, para descubrir aquello que muestra tener efectos perdurable y distinguirlo de lo que no resiste el paso del tiempo. De este modo puede destacar lo que es susceptible de ser proyectado hacia el futuro desde la perspectiva del presente.

La apertura al futuro es propia de un ser finito, que tiene limitaciones y deseos, que aspira a supe- 
rar su estado de precariedad y confía en que ello es posible, es decir que tiene esperanza. La esperanza se refiere a la liberación del desgarro espiritual y material que generan las injusticias infligidas a hombres y mujeres concretos sometidos a poderes externos sobre los que no poseen ninguna capacidad de control y que se asientan en pecados individuales y estructurales. La esperanza es liberadora porque no deja al hombre atado de manos e inerme frente a sus desgracias, sino que moviliza sus energías para luchar contra ellas por una vida mejor. Pero es doblemente liberadora en la perspectiva cristiana porque la fe tiene un carácter dinámico que dispone al hombre para vivir la historia como una realidad que no está clausurada, sino que es meta por cumplir. Por otra parte, como bien recordaba Juan Noemi en un libro temprano sobre esperanza y libertad, la afirmación de Dios como sentido y fin del hombre especifica el carácter libre de este al conectarlo con su propio fundamento ( $i E s$ la esperanza cristiana liberadora? Ediciones Paulinas, 1990, p. 35). O dicho con las palabras de San Pablo, que Juan cita: "Porque el Señor es el Espíritu y donde está el Espíritu del Señor allí está la libertad." $(2$ cor 3,17$)$

Filosofía y Teología comparten la característica esencial de ser un quehacer de la razón que no funda un saber meramente objetivo, sino la vida de los que piensan en una situación histórica concreta. En tanto que operaciones de la razón ellas interpretan una realidad absoluta que tiene sentido relativo a la existencia que es finita desde el punto de vista del conocer y del poder, pero infinita desde el punto de vista de la verdad, la libertad y la dignidad humanas.

Las preguntas, respuestas y contrapreguntas que caracterizan el quehacer filosófico y teológico se realizan desde un centro que es el lenguaje. No es casual que el término griego lógos sirva para designar tanto la razón como la palabra, ni tampoco es casual que el Prólogo del Evangalio de San Juan se valga del lógos para designar la conjunción de la Palabra eterna de Dios y el acontecimiento singular de la encarnación en el Jesús histórico. Como lugar y expresión de la razón, el lenguaje es un centro que mira hacia los dos lados: el lado de lo absoluto e infinito, y el lado de lo humano y finito. En el lenguaje como centro comparecen el lado objetivo y el lado subjetivo de la verdad. En él se contienen palabras $y$ juicios finitos, limitados y parciales que remiten a infinitas palabras posibles que remiten a una verdad igualmente infinita, imposible de agotar por el lenguaje humano. 
No obstante, podemos acceder parcialmente o relativamente a la verdad total o absoluta. Hay verdad cuando el objeto al que se dirige la conciencia en cualquiera de sus formas se hace presente tal como es pensado por ella. La filosofía y la teología no tendrían sentido si no aceptaran que el conocimiento de la verdad es posible en este sentido. Este conocimiento deja de ser posible cuando la incertidumbre se constituye en obstáculo subjetivo para que el objeto se haga presente. Dudar y conocer la verdad no son de suyo términos excluyentes. Solo llegan a serlo cuando la duda es de tal magnitud que excluye todo grado de creencia o certeza. La creencia proporciona la plataforma mínima necesaria para que se pueda desencadenar el proceso de la búsqueda de la verdad, pero no es suficiente por sí misma, sino que está naturalmente llamada a desplegarse en esta búsqueda. A ello se refería San Anselmo de Canterbury con la frase que Juan Noemi cita con frecuencia: "Creo para entender".

La creencia que está en la base de la búsqueda de la verdad no es necesariamente la del hombre religioso, como en el caso de San Anselmo, pero esta última no tiene en ningún caso una dignidad menor que la fe natural que permite acceder a la verdad filosófica.
Por otra parte, el conocimiento de la verdad supone algo más que algún grado de creencia o certeza. Se requiere también que lo que se dice con verdad y certeza no sea arbitrario, sino que posea una justificación o un fundamento de legitimidad. La función de proporcionar ese fundamento fue la tarea que se impuso a sí misma la filosofía moderna a partir de René Descartes. Pero si bien esta filosofía pone la discusión sobre el método en un lugar central de su reflexión, esa discusión no tiene que ver con la finalidad última de la filosofía, sino con el medio o el camino que hace posible alcanzar tal finalidad. El fin de la filosofía a cuyo servicio se encuentra el método es la sabiduría, en su doble vertiente, tanto teórica como práctica. El fin teórico es la verdad, y el fin práctico es la libertad. Ambas finalidades son inseparables y se condicionan recíprocamente en la búsqueda de una plenitud de vida personal y comunitaria. La verdad nos hace libres y la libertad es la condición del acceso a la verdad y de su goce.

La teología cristiana comparte la misma convicción, pero no la hace depender de un método de la razón, sino de una revelación que nace de la iniciativa de Dios, recibida y trasmitida en una comunidad de fe que es anterior a la decisión personal de plegarse a ella. 
Dios se automanifiesta al hombre en la historia y le interpela, llamándolo a reconocer su verdad en la persona de Jesucristo. La fe es la respuesta del hombre a este llamado que involucra la totalidad de su ser: su intelecto, sus emociones y su acción. Pone en juego el respeto a su dignidad personal, pues implica fidelidad a la posibilidad fundamental de fundar su vida en su creador y redentor. Este respeto a la personalidad individual lleva también al respeto activo de la individualidad del otro, que es diferente, pero igualmente valiosa en el marco de una comunidad de personas que reconocen un destino común.

La función del lenguaje alcanza su plenitud en el ejercicio de la comprensión y el entendimiento. Por eso el método de la filosofía y de la teología actuales tiene que ser intersubjetivo o dialógico. La filosofía, que es también base racional de la teología, se atiene a las cosas mismas, pero esa mismidad de las cosas no es siempre igual ni tiene el mismo sentido para todos y en todo lugar. El diálogo es un fenómeno social, y presupone, por lo tanto, que se dé en el marco del reconocimiento mutuo, la mutua aceptación, y también de las luchas y conflictos que son propias de las relaciones entre los seres humanos. Por eso es necesario respetar las condiciones que hacen posible el encuentro de los puntos de vista, las que no dependen solamente de la voluntad de los interlocutores, sino que radican también en la naturaleza misma de la comunicación y están dadas de antemano por las estructuras lógico-semánticas, pragmáticas y retóricas del lenguaje y por tradiciones históricas y culturales compartidas.

El diálogo auténtico combina los principios de la caridad y de la claridad. En virtud del primero cada uno está dispuesto a entender los argumentos del otro en la mejor de sus versiones posibles, aceptando de antemano que pudiera estar en posesión de un conocimiento superior. En virtud del principio de la claridad los argumentos se exponen del modo que mejor pueda ser comprendido por el otro, para que pueda aceptarlos o refutarlos con plena conciencia de lo que está en juego.

El diálogo de la razón con la fe que se da tanto al interior de la teología como desde la filosofía puede ser un caso ejemplar de encuentro entre posiciones distintas pero complementarias, que se enriquecen y a la vez se depuran entre sí. Así como la razón puede preservar a la fe de peligros como el fundamentalismo, el fanatismo, el fideísmo o la superstición, la fe 
religiosa puede a su vez contribuir para que el filósofo se haga consciente del peligro de pensar que con el mero recurso a una razón encerrada en sí misma será capaz de dar cuenta de todo lo real y justificar conductas con prescindencia de toda referencia a contextos históricos y contingencias sociales o culturales. El ejercicio efectivo de la razón es inseparable de tradiciones, creencias y autoridades. Se puede comprobar que el cristianismo ha contribuido a transformar a la filosofía abriendo a la razón humana perspectivas que esta antes no había descubierto, como por ej. la idea de un Dios único y trascendente, de la creación del mundo, de la libertad subjetiva y del sentido finalista de la historia. Pero también es evidente el aporte de la filosofía al esclarecimiento de conceptos teológicos capitales como los de naturaleza y persona, además del desarrollo de los métodos lógicos y epistemológicos de los que depende como saber teórico.

En el diálogo entre la razón y la fe, también cumplen un papel importante el sentido común y la sabiduría popular, siempre que se los entienda en un sentido indicativo, no fundante, puesto que proporcionan una base material de precomprensiones que alimentan la reflexión, y funcionan como una instancia de control frente a posiciones extremas. Los ejemplos, alegorías, mitos, símbolos y metáforas inspiradas en la vida cotidiana y en el drama humano han probado ser fecundos e iluminadores tanto para la filosofía como para la teología, como lo muestran en el mundo antiguo los ejemplos de Platón y San Agustín, y en la época contemporánea Wittgenstein y Von Balthasar, entre otros. Una cantera inagotable de estos materiales se encuentra en las propias Sagradas Escrituras, a las que Juan Noemi acude frecuentemente en toda su obra, y que, independientemente de su aceptación como revelación divina, constituyen también para la filosofía un depósito de experiencias de humanidad que no debería ser desaprovechado.

Concluyo agradeciendo una vez más la oportunidad de compartir este espacio de encuentro con un auténtico pensador e interlocutor de la filosofía desde la reflexión teológica como lo ha sido -y espero siga siendo por mucho tiempo- el profesor Juan Noemi. 
